Motrivivência $\quad$ v. 27, n. 46, p. 230-240, dezembro/2015

\title{
INJÚRIA RACIAL NO FUTEBOL BRASILEIRO: uma análise sócio-histórica de alguns casos (não tão) esporádicos ocorridos nos últimos anos
}

\author{
Maria Thereza Oliveira Souza \\ Larissa Jensen² \\ André Mendes Capraro 3 \\ Everton de Albuquerque Cavalcanti4
}

\section{RESUMO}

Apesar do discurso das autoridades que gerenciam o futebol no âmbito global contrários a qualquer forma de discriminação, sobretudo as de cunho racial, a reincidência de casos prossegue. Embora se caracterize como algo singular por parte da maioria dos pesquisadores, o racismo no futebol apresenta elementos gerais que, por vezes, são ignorados. Vide exemplos das ocorrências com alguns jogadores brasileiros, como Aranha, Arouca, Daniel Alves, Tinga e Roberto Carlos, bem como do árbitro Márcio Chagas da Silva. Vários destes casos foram pesquisados academicamente, porém, como são análises pontuais (estudos de caso), acabam não articulando o fenômeno racismo no futebol como um todo. Portanto, o objetivo deste artigo é apresentar uma reflexão acerca deste fenômeno social lamentável que - por maior que sejam as campanhas de conscientização por parte das autoridades e da imprensa - não apresentam indícios de que estão recrudescendo. A pesquisa é pautada nos procedimentos da história do tempo presente.

Palavras-chave: Injúria Racial; Futebol; Impunidade

1 Mestranda em Educação Física. UFPR, Curitiba/Paraná, Brasil. E-mail: mariathereza_souza93@yahoo.com.br 2 Mestranda em Educação Física. UFPR, Curitiba/Paraná, Brasil. E-mail: lari-jensen@hotmail.com

3 Doutor em História. Professor Adjunto da UFPR, Curitiba/Paraná/Brasil. E-mail: andrecapraro@onda.com.br

4 Doutorando em Educação Física. UFPR, Curitiba/Paraná/Brasil. E-mail: profevertoncavalcanti@gmail.com 


\section{INTRODUÇÃOO}

Assim como em várias esferas sociais, a prática esportiva está repleta de exemplos de injúria racial ${ }^{6}$. Mesmo no Brasil, país tão marcado pela miscigenação, os episódios de agressões verbais proferidos por conta de diferenças na cor da cútis acontecem regularmente por anos.

Apesar das constantes campanhas e discursos por parte das entidades regulamentadoras contra quaisquer tipos de discriminação em partidas de futebol, a reincidência desses dá indícios de que o problema está bem longe de ser resolvido ${ }^{7}$. Portanto, o objetivo de tal pesquisa é apresentar uma reflexão sobre esse lamentável fenômeno social, com foco nas punições para atos desta natureza, que parecem estar sendo demasiadamente brandas seja por parte da FIFA, da CONMEBOL ou mesmo das confederações nacionais de futebol, com raríssimas exceções, e dessa forma, testar a hipótese de que os casos de racismo já não podem mais ser tratados como fenômenos isolados, como reforçado por parte significativa de envolvidos com o futebol mundial - assim como é visto no seguinte depoimento do técnico da seleção espanhola, Vicente Del Bosque, publicado pela Folha online, ao comentar o ato de racismo contra o jogador brasileiro Daniel Alves em jogo pelo Campeonato Espanhol da temporada 2013/2014:

"Tem gente que utiliza o futebol para fazer propaganda de um assunto grave. Não creio que seja um problema da Espanha. São fatos isolados de algumas pessoas que se aproveitam desse esporte. No futebol, não há racismo de forma geral". (FOLHA DE SÃO PAULO ONLINE, 2014).

E na declaração de Edson Arantes do Nascimento, mundialmente conhecido como Pelé e, que possui um forte capital simbólico no campo futebolístico, ao criticar o goleiro "Aranha" por retaliar as ofensas vindas da arquibancada adversária durante a disputa de um jogo da Copa do Brasil de 2014 (o episódio será detalhado a seguir), com as seguintes palavras:

"O Aranha se precipitou em querer brigar com a torcida. Se eu fosse querer parar o jogo cada vez que me chamassem de macaco ou crioulo, todos os jogos iriam parar. O torcedor grita mesmo. Temos que coibir o racismo. Mas não é num lugar publico que você vai coibir. O Santos tinha Dorval, Coutinho, Pelé... todos negros. Éramos xingados de tudo quanto é nome. Não houve brigas porque não dávamos

5 Essa pesquisa contou com o apoio financeiro da Coordenação de Aperfeiçoamento de Pessoal de Nível Superior (CAPES).

6 Enquanto a injúria racial consiste em ofender a honra de alguém valendo-se de elementos referentes à raça, cor, etnia, religião ou origem, o crime de racismo atinge uma coletividade indeterminada de indivíduos, discriminando toda a integralidade de uma raça. (Conselho Nacional de Justiça).

7 Afora os casos envolvendo atletas brasileiros, podem-se citar alguns casos muito repercutidos: Luis Suárez (Liverpool) contra Patrice Evra (Manchester United) em 2011; a afronta de torcedores do Zaragoza ao camaronês Samuel Eto'o, que atuava pelo Barcelona, em 2006. Yaya Touré ofendido por torcedores em sua conta no Twitter; Selassie e Balotelli que ouviram cânticos racistas vindos da torcida adversária durante partidas da Eurocopa de 2012, na Republica Tcheca e Rússia, respectivamente; Prince Boateng (que atuava pelo Milan), que deixou o gramado após ser insultado por torcedores do Pro Patria, no ano de 2013, e foi acompanhado por seus companheiros de clube. 
atenção. Quanto mais se falar, mais vai ter racismo". (BALTAR, 2014).

Outro ponto a ser investigado é o fato de que as pesquisas que tratam desse tema no futebol, em quase sua totalidade, também o estudam como casos isolados, ou seja, são análises de episódios. Alguns desses serão identificados no decorrer desse artigo.

\section{METODOLOGIA}

A metodologia utilizada diz respeito a um estudo focado nos preceitos da História do Tempo Presente, pois tal proposta se associa muito bem à narrativa jornalística:

Entre a narrativa jornalística e a narrativa da História há um discurso que se refere sempre ao presente, ao momento atual, àquilo que é provisório e é exatamente o que, confere uma singularidade à narrativa jornalística, que é uma narração contínua da história do presente imediato, consideração que direciona nosso pensamento para a compreensão de que o jornalismo e suas narrativas estão no bojo do nosso presente histórico. (ANDRADE, 2010).

Dessa forma, as fontes que alimentaram a pesquisa são aquelas advindas do trabalho da imprensa, e, sobre esse método, a historiadora Tania Regina de Luca explica que:

O pesquisador dos jornais e revistas trabalha com o que se tornou notícia, o que por si só já abarca um espectro de questões, pois será preciso dar conta das motivações que levaram à decisão de dar publicidade a alguma coisa. [...] Em síntese, os discursos adquirem significados de muitas formas, inclusive pelos procedimentos tipográficos e de ilustração que os cercam. A ênfase em certos temas, a linguagem e a natureza do conteúdo tampouco se dissociam do público que o jornal ou revista pretende atingir. (LUCA, 2005, p. 140).

As fontes utilizadas no presente artigo foram encontradas integralmente no formato online, sendo que as especificidades da publicação virtual da notícia são a velocidade com que o conteúdo chega ao público, a efemeridade das informações e a interatividade proporcionada pelos portais, que na maioria das vezes usam diferenciados mecanismos para manter o leitor conectado a sua página. Afora isso, o conteúdo pode ser analisado com a utilização dos mesmos mecanismos ao formato impresso de revistas e jornais.

\section{Relato de alguns casos "isolados" no Brasil}

O Brasil foi palco de alguns exemplos muito marcantes em curto espaço de tempo. Apenas no ano de 2014 podemos citar vários deles. Um dos mais recentes e que gerou uma penalização mais impactante, aconteceu durante a partida realizada em 28 de agosto de 2014, entre as equipes Grêmio Foot-ball Porto Alegrense e Santos Futebol Clube, valida como confronto de ida pelas oitavas de final da Copa do Brasil.

O goleiro santista Mário Lucio Duarte Costa, mais conhecido como "Aranha", foi ofendido com injúrias raciais proferidas por alguns torcedores gremistas que estiveram presentes ao estádio. O Superior Tribunal de Justiça Desportiva (STJD) excluiu o Grêmio Foot-ball Porto Alegrense da competição em julgamento realizado em 
3 de setembro de 2014, definindo também uma multa de 50 mil reais pelas injurias ao jogador santista (apesar de exemplar punição referente a exclusão da competição, a multa de 50 mil reais é um valor financeiro pouco significativo para grande parte dos clubes brasileiros). Esse julgamento foi feito após a grande repercussão midiática e a consequente comoção pública que o caso gerou, movida pela revolta do atleta, que durante a partida chamou atenção do árbitro várias vezes para as agressões verbais que estavam ocorrendo e depois do término da mesma, mostrou-se incrédulo com toda a situação, deixando claro que não iria aceitar o episódio de forma passiva. Vale salientar que o Grêmio acabou derrotado na ocasião pelo placar de $2 \times 0$, sendo assim, dificilmente conseguiria reverter tal situação no jogo de volta na cidade de Santos, para então passar de fase na competição nacional.

O episódio saiu do âmbito esportivo no momento em que "Aranha" prestou queixa na Delegacia de Polícia e Patrícia Moreira (jovem que foi flagrada pelas câmeras de TV chamando o goleiro de "macaco") viu sua vida ser transformada por conta de seu ato reprovável. Ela teve a sua casa apedrejada, foi demitida de seu emprego e precisou se refugiar na casa de parentes para se proteger de possíveis retaliações por parte de pessoas que se juntaram de forma mais agressiva a defesa do jogador ofendido. Fato que de certa forma impressiona é que pouco tempo após esse episódio, Santos e Grêmio voltaram a se enfrentar, novamente com mando do time gaúcho, e Aranha foi vaiado por grande maioria da torcida adversária a cada toque na bola, ou seja, concordando ou não com atos de alguns torcedores na partida anterior, quase a totalidade desaprovara a reação do goleiro e a consequente penalização de seu clube.

O caso ganhou grande repercussão internacional, sendo que alguns periódicos analisaram as punições esportivas ao clube como severas, como levantou o site do Globo Esporte:

O noticiário espanhol "As" tratou as punições como "severas", e destacou a comoção nacional que tomou conta do país após o incidente. O britânico "Daily Mail" ressaltou os quatro títulos da Copa do Brasil conquistados pelo Grêmio, além da presença de Felipão como treinador da equipe.

Scolari também foi manchete no jornal Record, de Portugal. Segundo o site, um dos principais objetivos do comandante para a temporada - o título da Copa do Brasil - "cai por terra" com a punição. O americano "USA Today", e o "New Zeland Herald", da Nova Zelândia, também noticiaram o julgamento. (GLOBO ESPORTE, 2014).

O modo como o fato é noticiado em quase todos esses jornais transparece que a maioria entendeu a punição como exagerada, como se vê nesses trechos extraídos do "As", do "USA Today" e do "Daily Mail":

Punición severa contra el racismo en Brasil. El Gremio de Porto Alegre fue excluido este miércoles de la disputa por el título de la Copa de Brasil por los gritos de "mono" procedentes desde de la grada de su estadio contra el portero Aranha, del Santos... La dura sentencia fue dictada por el Superior Tribunal de Justicia Deportiva (STJD), tras casi cuatro horas de audiencia en Río de Janeiro, que también suspendió por 45 días al árbitro del partido, Wilton Pereira Sampaio, por no haber relatado el incidente en su informe. (KALLÁS, 2014) 
The tribunal earlier this month, in an unprecedented ruling against a top Brazilian team, had banned Gremio from the Brazilian Cup after a small group of fans called Santos goalkeeper Aranha a "monkey" and imitated monkey noises. (USA TODAY, 2014)

Wednesday's ruling comes less than a week after a small group of fans called Santos goalkeeper Aranha a "monkey" in a Brazilian Cup match at the Arena Gremio. Some also imitated monkey noises towards the player. (AZZONI, 2014)

Dos três periódicos citados, apenas o "As" é um jornal especializado em esporte. Os demais são caracterizados como grandes portais e tais notícias foram publicadas nas suas respectivas páginas esportivas. Apesar disso, o teor das palavras é bastante similar e a visão de que o ato de um grupo pequeno de torcedores gerou consequências graves para o clube parece ser o que mais surpreende ambos, possibilitando a interpretação de que os meios de comunicação reforçam o tratamento dos casos como fenômenos isolados.

As atitudes racistas no futebol não se restringem às ofensas a jogadores. Um caso que ficou muito conhecido foi o que aconteceu contra o ex-árbitro Márcio Chagas da Silva após jogo disputado entre o Clube Esportivo de Bento Gonçalves e Veranópolis Esporte Clube Recreativo e Cultural, valido pelo campeonato gaúcho desse mesmo ano. Após a partida, Márcio encontrou seu carro depredado e com bananas sobre a porta. Ele registrou os fatos na súmula e fez um boletim de ocorrência, no qual também afirmou que atos racistas aconteceram durante toda a disputa do torneio estadual.

O caso foi a julgamento no TJD (Tribunal de Justiça Desportiva) estadual e o Esportivo, por ser o mandante da partida, perdeu nove pontos na classificação. Punição que só foi estabelecida após protestos dos próprios árbitros do referido campeonato nos jogos que sucederam ao fato, pois a primeira decisão do Tribunal havia sido uma multa de 30 mil reais e a perda de cinco mandos de campo ao clube.

Em outro torneio estadual, dessa vez no Campeonato Paulista, o atleta Marcos Arouca da Silva, mais conhecido como "Arouca", que então atuava pelo Santos Futebol Clube, foi ofendido por torcedores do Mogi Mirim Esporte Clube na saída para os vestiários. O árbitro da partida não relatou o acontecido na súmula e os policiais que estavam fazendo a segurança no local não identificaram os agressores. Arouca e seu técnico Oswaldo de Oliveira declararam-se tristes e cansados com esse tipo de situação; defenderam também que se deveria agir com mais severidade nos julgamentos de tais situações.

Apesar de todos esses casos, as competições do ano de 2015 começaram da mesma forma, e na atual edição da Taça Libertadores da América uma nova ofensa já foi presenciada. O atleta Elias que atua pelo Sport Club Corinthians Paulista foi chamado de "macaco" pelo jogador uruguaio Cristian Gonzalez que defende as cores do Danúbio. O ato, imperdoável para alguns, inclusive pela própria constituição brasileira, foi relativizado pelo delegado da CONMEBOL responsável pelo controle de tal partida, segundo o mesmo (que também é Secretário Geral da entidade continental), a ofensa não é considerada racismo em alguns países sul-americanos.

A competição continental também foi palco de outro episódio lamentável e que tomou conta dos noticiários pelo 
mundo, cerca de uma década antes desse fato. O atacante Edinaldo Batista Libânio, conhecido como "Grafite", que defendia a equipe do São Paulo Futebol Clube, foi ofendido verbalmente por palavras racistas proferidas pelo zagueiro argentino Leandro Desábato, que atuava no Quilmes Atlético Club, na fase de grupo da Libertadores de 2005. O atleta foi preso ainda no gramado e permaneceu detido durante dois dias. Após pagar multa de dez mil reais, ele retornou a Argentina, prometendo ser solicito a todos os trâmites do processo criminal. Apesar disso, o atacante brasileiro resolveu retirar a queixa.

$\mathrm{Na}$ época, tal episódio foi amplamente debatido e muitas questões vieram à tona em sua decorrência. Hélio Schwartsman, que escrevia para a Folha online na ocasião, foi enfático ao afirmar que a lei não deveria ser cumprida com tanto rigor naquele caso, defendendo que, provavelmente, o que as autoridades fizeram foi também um ato xenofóbico:

Nesse quadro, a prisão do zagueiro argentino desponta como escandalosa. Para começar as ofensas foram trocadas no contexto de uma partida de futebol, na qual jogadores adversários sempre travam uma pequena batalha psicológica pessoal cujas armas são palavrões e provocações. O que me parece muito mais grave, porém, é o excesso de zelo com que as autoridades cumpriram a lei. São raríssimos para não dizer inexistentes os flagrantes pelo crime de injúria neste país. Fica a suspeita de que Desábato foi transformado numa espécie de bode expiatório. Paga não apenas por suas ações, mas pelas de gerações e gerações de jogadores argentinos no âmbito de uma rivalidade futebolística quase centenária com o Brasil. Ao agir tão diligentemente contra o argentino, nossas autoridades parecem incorrer na mesma espécie de preconceito xenófobo que os dispositivos anti-racismo da Constituição visam a coibir. (SCHWARTSMAN, 2005).

O escritor deixa clara sua contundente opinião: a lei não deveria ser levada ao pé da letra, mesmo havendo provas do ato de injúria racial. O mesmo relativiza as ofensas, reforçando uma ideia que parece estar presente em grande parcela da sociedade, a de que, na maioria das vezes, esse tipo de acontecimento deve ser relevado, supostamente por não apresentar uma ameaça séria à ordem social.

Academicamente, esse caso foi tratado nos artigos "Racism in South Americam Soccer: Grafite Versus Desábato Case" de Everton Cavalcanti e André Mendes Capraro e "Uma análise sobre o caso 'Grafite $\mathrm{x}$ Desábato' à luz do 'racismo à brasileira' de Bruno Otávio de Lacerda Abrahão e Antonio Jorge Soares).

Recentemente o atleta Danilo Larangeira teve sua pena decretada pela justiça comum a pagar aproximadamente 566 mil reais a entidades de fim social por injúria racial contra o atleta Manoel Messias Silva Carvalho desferida em jogo válido pela Copa do Brasil de 2010. Na época Danilo atuava pela Sociedade Esportiva Palmeiras e Manoel pelo Clube Atlético Paranaense.

No ano de 2006, Antonio Carlos Zago, que então atuava pelo Esporte Clube Juventude teve sua vitoriosa carreira manchada por um grave ato de racismo. O atleta desferiu uma cotovelada em Jeovânio Rocha do Nascimento, que atuava pelo Grêmio Foot-Ball Porto Alegrense e foi expulso pelo árbitro da partida. Ao sair de campo Antonio Carlos esfregou a pele do braço em direção a Jeovânio, em clara tentativa de demonstrar 
superioridade por sua cor de pele. O Atleta foi suspenso por 120 dias.

Em 2009, o atleta Elicarlos Souza Santos, que atuava pelo Cruzeiro Esporte Clube, acusou o jogador argentino do Grêmio Foot-ball Porto Alegrense, Maxi Rodrigues, de tê-lo chamado de "macaco" em jogo pela semifinal da Copa Libertadores da América. Este negou as acusações e o seu técnico Paulo Autuori, mais preocupado em defender os interesses de seu clube do que com o episódio propriamente dito, chegou a declarar que: "Todo mundo sabe que isso não dá em nada. Temos que nos preocupar com coisas mais sérias. Todo dia existe racismo, vamos acabar com essa hipocrisia. Quero falar de futebol".

\section{Casos em outros países envolvendo atletas brasileiros}

No dia 12 de fevereiro de 2014, em partida disputada pela Copa Bridgestone Libertadores, entre Cruzeiro Esporte Clube e o clube peruano Asociación Civil Real Atlético Garcilaso, na cidade de HuanCayo houve a ocorrência de mais um caso de racismo no futebol. Nesta disputa, ao adentrar o campo, aos vinte minutos do segundo tempo, o atleta Paulo César Fonseca do Nascimento, também chamado de Tinga, sofreu insultos raciais, proferidos pela torcida peruana, os quais consistiam em imitações de guinchos de macacos emitidos a cada vez que o atleta tocava a bola. Apesar da indignação causada por tais insultos, nenhuma atitude foi tomada por parte da arbitragem, do delegado da CONMEBOL presente no evento, da segurança do clube, ou da própria polícia local. A disputa transcorreu dessa maneira até o fim do tempo regulamentar.
Após o jogo, Tinga declarou que trocaria todas as suas conquistas no futebol caso isso acabasse com os atos de racismo. A presidente do Brasil e o presidente peruano pronunciaram-se de forma contrária ao ocorrido e em defesa do atleta. O caso ganhou grande destaque na mídia e após 39 dias da ocorrência da manifestação discriminatória, A CONMEBOL anunciou a punição dada à Asociación Civil Real Atlético Garcilaso: multa de US\$12 mil, cerca de $R \$ 28$ mil (naquela época), referente à pena pelos insultos proferidos à Tinga por alguns integrantes da torcida peruana (CONMEBOL, 2014). Vale aqui ressaltar que os valores aplicados sob a forma de multa são irrisórios em se tratando de clubes de futebol que disputam um torneio de porte intercontinental. Para que se tenha ideia da desproporção da multa aplicada ao clube peruano, basta saber que o elenco do mesmo estava avaliado na época do episódio em cerca de 2 milhões de reais.

Casos semelhantes a esse ocorreram também em território europeu. O que mais atingiu os meios de comunicação foram os atos contra o lateral brasileiro Daniel Alves, jogador do Futbol Club Barcelona, em partida contra o Villarreal Club de Fútbol pelo Campeonato Espanhol, no dia 27 de abril. O acontecimento tomou grandes proporções, já que o jogador teve atitude inusitada no momento em que um torcedor adversário jogou uma banana em sua direção. Em imagem registrada e assistida globalmente, tranquilamente, Alves descascou, comeu a fruta e em seguida cobrou o escanteio, como se nada de anormal tivesse ocorrido. Prontamente, muitos canais esportivos, revistas, e jornais repercutiram o caso e muitos amigos pessoais de Daniel, pessoas públicas e atletas juntaram-se a uma campanha 
contra o racismo, que tinha a frase "Somos todos macacos" como slogan.

Essa estratégia foi amplamente criticada por alguns segmentos, com a alegação de que essa frase teria um efeito oposto do que estava sendo objetivado. Quanto a isso, Daniel Alves foi enfático: “É hipocrisia criticar uma campanha contra o racismo. Os críticos estão se apegando ao contexto (o episódio da banana), e não ao objetivo, que é conscientizar as pessoas de que somos todos humanos e somos todos iguais".

Assim como Daniel Alves, o atleta brasileiro Roberto Carlos teve uma banana atirada em sua direção por um torcedor da torcida adversária, dessa vez o país era a Rússia, no ano de 2011, quando atuava pelo Anzhi Makhachkala. O jogador retirou-se de campo e posteriormente declarou que estava cansado da reincidência de atitudes daquela natureza. Sua decisão foi apoiada por seus companheiros de clube e por seu técnico.

\section{CONCLUSÕES}

Levantou-se a hipótese de que existe um esforço por parte das autoridades ligadas ao meio futebolístico em caracterizar os episódios de racismo como algo isolado, singular e pouco frequente. Além disso, os meios de comunicação parecem atuar no sentido de reforçar tais caracterizações. Entretanto, a soma de todos estes aponta para uma possível "endemia" mundial. Tanto que mesmo no Brasil, país caracterizado pela heterogeneidade racial e por uma suposta tolerância entre as diversas raças e biótipos, os casos são recorrentes. Sendo assim, confirma-se também que as punições aplicadas são brandas, meramente simbólicas, tendo em vista as cifras que giram em torno do futebol de alto rendimento, à exceção do episódio envolvendo as equipes do Grêmio Foot-ball Porto Alegrense e o Santos Futebol Clube, chamado pela imprensa de "caso Aranha". Por outro lado, vale o reforço de que tal confronto já estava bastante desfavorável ao time punido, desta forma pode-se supor que a punição rigorosa se deu em condição de excepcionalidade.

É inevitável não alertar, em última instância, para a necessidade de pesquisas mais amplas focadas no racismo no futebol, já que os poucos estudos existentes tratam-se quase sempre de estudos de caso, ou seja, reforçando a ideia de que estes seriam ocasionais.

\section{REFERÊNCIAS}

ABRAHÃO, Bruno Otávio de Lacerda; SOARES, Antonio Jorge. Uma análise sobre o caso Grafite $X$ Desábato à luz do 'racismo à brasileira'. Esporte e Sociedade. Rio de Janeiro, n.5, p. 1-17, 2007.

AGUIAR, Liana. Daniel Alves: É hipocrisia negar racismo e criticar \#somostodosmacacos. BBC Brasil, 30 abr. 2014. Disponível em: <http://www.bbc.com/portuguese/ noticias/2014/04/140430_entrevista daniel_alves_la_an $>$. Acesso em: 10 maio 2015.

ANDRADE, Ana Claudia Pacheco de. Jornalismo e História: da notícia e produção da fonte à análise da realidade. In: Encontro Estadual de História da ANPUH - BA, 5., Salvador, 2010. Anais eletrônicos, Salvador, 2010. Disponível em: < http://vencontro. anpuhba.org/anaisvencontro/A/Ana 
Claudia_Pacheco_de_Andrade.pdf $>$. Acesso em: 20 ago. 2015.

AZZONI, Tales. Gremio fined and banned from Brazilian Cup after fans are found guilty of racist abuse. MAILOnline, 03 set. 2014. Disponível em: < http:// www.dailymail.co.uk/sport/football/ article-2742751/Gremio-fined-bannedBrazilian-Cup-fans-guilty-racist-abuse. html > . Acesso em: 12 maio 2015.

BALTAR, Marcelo. Pelé faz crítica a Aranha: "Quanto mais se falar, mais vai ter racismo". Globo Esporte. 10 set. 2014. Disponível em: < http:// globoesporte.globo.com/futebol/ selecao-brasileira/noticia/2014/09/ pele-sobre-participacao-brasileira-nacopa-do-mundo-um-desastre.html > . Acesso em: 15 maio 2015.

CAVALCANTI, Everton Albuquerque; CAPRARO, André Mendes. Racismo no Futebol Sul-Americano: o caso Grafite versus Desábato / Racism in South American Soccer: Grafite Versus Desábato Case. Motriz. Rio Claro: v. 15, n. 04, p. 741-748, out./dez. 2009.

CONSELHO NACIONAL DE JUSTIÇA.

Conheça a diferença entre racismo e injúria racial. 08 jun. 2015. Disponível em: < http://www.cnj.jus.br/noticias/ cnj/79571-conheca-a-diferenca-entreracismo-e-injuria-racial $>$. Acesso em: 10 jun. 2015.

ESPORTE INTERATIVO. Para Conmebol, Elias ser chamado de "macaco" pode não ser racismo. 02 abr. 2015. Disponível em: < http://esporteinterativo.com.br/ futebol-brasileiro/para-conmebol-eliasser-chamado-de-macaco-pode-nao-serracismo/> . Acesso em: 10 maio 2015. FOLHA DE SÃO PAULO. Para técnico da Espanha, casos de racismo no futebol são fatos isolados. 29 abr. 2014. Disponível em: < http://www1.folha.uol.com.br/ esporte/folhanacopa/2014/04/1447044tecnico-da-selecao-espanhola-diz-quenao-ha-racismo-no-futebol.shtml > . Acesso em: 10 maio 2015.

GLOBOESPORTE. Exclusão do Grêmio da Copa do Brasil ganha destaque na imprensa mundial. 03 set. 2014. Disponível em: <http://globoesporte. globo.com/futebol/times/gremio/ noticia/2014/09/exclusao-do-gremioda-copa-do-brasil-ganha-destaque-naimprensa-mundial.html >. Acesso em: 15 maio 2015.

GLOBOESPORTE. Para esclarecer caso de racismo, Maxi López e Elicarlos param na delegacia. 25 jun. 2009. Disponível em: <http://globoesporte. globo.com/Esportes/Noticias/Futebol/ Libertadores/0,,MUL1206968-9851,00PARA + ESCLARECER + CASO + DE + RACISMO + MAXI + LOPEZ +E + ELIC ARLOS + PARAM + NA + DELEGACIA. html > . Acesso em: 15 maio 2015.

SCHWARTSMAN, Hélio. Lei e Raça. Folha online, 21 abr. 2005. Disponível em: < http://www1.folha.uol.com. br/folha/pensata/helioschwartsman/ ult510u356106.shtml >. Acesso em: 24 ago. 2015.

KALLÁS, Fernando. El Gremio, expulsado de la Copa de Brasil por actos racistas. AS, 03 set. 2014. Disponível em: < http:// futbol.as.com/futbol/2014/09/03/ internacional/1409780038_424244. html > . Acesso em: 12 maio 2015.

LANCENET. Árbitro Márcio Chagas relata racismo e depredação de carro no Gauchão. 06 mar. 2014. Disponível em: < http://www.lancenet.com.br/minuto/ Arbitro-Marcio-Chagas-depredacao- 
Gauchao_0_1096690453.html >. Acesso em: 15 maio 2015.

LUCA, Tania Regina de. História dos, nos e por meio dos periódicos. In PINSKY, Carla Bassanezi (Org.). Fontes

Históricas. São Paulo: Contexto, 2008, p. 111-153.
USATODAY. Tribunal keeps Gremio out of Brazillian Cup. 26 set. 2014. Disponível em: < http://www.usatoday. com/story/sports/soccer/2014/09/26/ tribunal-keeps-gremio-out-of-braziliancup/16266173/>. Acesso em: 13 maio 2015.

RACIAL INJURY ON BRAZILIAN'S FOOTBALL: a sociohistorical analysis of some sporadic (not so) cases occurred in recent years

\begin{abstract}
Although the discourse of the authorities who manage football at the global level oppose any form of discrimination, especially the racial nature, the recurrence of cases continues. Even though many researchers characterized as something unique, racism in football presents general elements that sometimes are ignored. Examples can be seen in the cases of Brazilian players such as Aranha, Arouca, Daniel Alves, Tinga and Roberto Carlos, as well as the Brazilian arbiter Marcio Chagas da Silva. Several of them were studied academically, however, as they are specific analyzes (case studies), they don't articulate racism phenomenon in football as a whole. Therefore, the aim of this article is to present a reflection of this unfortunate social phenomenon that have no indications that are making a comeback - however there are lots of awareness campaigns by the authorities and the press. The research is guided by procedures from the present history methodology.
\end{abstract}

Keywords: Racial Injury; Soccer; Impunity

INSULTO RACIAL EN FÚTBOL BRASILEÑO: un análisis socio-histórico de algunos casos (no tan) esporádicos en los últimos años

\title{
RESUMEN
}

A pesar del discurso de las autoridades que manejan el fútbol a nivel mundial en contra de cualquier forma de discriminación, en particular la naturaleza racial, la recurrencia de casos continúa. Aunque caracterizado como algo único de la mayoría de los investigadores, el racismo en el fútbol presenta elementos generales que a veces son ignorados. Ver ejemplos de eventos con algunos jugadores brasileños como Aranha, Arouca, Daniel Alves, Tinga y Roberto Carlos y el árbitro Marcio Chagas da Silva. 
Varios de estos casos han sido investigados académicamente, sin embargo, como son análisis específicos (estudios de caso), acaban no articulando el fenómeno del racismo en el fútbol en su conjunto. Por lo tanto, el propósito de este artículo es presentar una reflexión sobre este fenómeno social lamentable que no tienen indicaciones de que están haciendo una reaparición. La investigación se guía en los procedimientos de la historia del momento actual.

Palabras clave: Insulto Racial; Fútbol; Impunidad

Recebido em: setembro/2015 Aprovado em: novembro/2015 